\title{
Purification System of Ocean Sludge by Using Coagulants and Activating Microorganisms
}

\author{
Kyoichi OKAMOTO $^{1}$ and Kenji HOTTA ${ }^{1}$ \\ ${ }^{1}$ CST, Nihon University, Japan
}

\begin{abstract}
Ocean sludge exerts a very big environmental load to local sea area. Here, attention was paid to micro-bubble technology for application to the purification of the sludge. The important point in this technique is to activate the bacteria existing in the area by micro-bubbles. We had developed a method for decomposing the sludge by using of microorganisms in an aerobic state by micro-bubble. Here, we have also a technique for purification by using "coagulants". So, we proposed the experimental way which hydrogen sulfide is reduced at first by using "coagulants" and then the nutrients will be reduced by activating microorganisms. Here, we used the detergents including enzyme as the microorganism activator. Our research object in this paper is to check the purification performance for sludge by our proposed experimental system. From the results of our experiments, we succeeded in reducing the time needed to purify the sludge, and we obtained the very good performance.
\end{abstract}

Keywords: Coagulants, Microorganism Activator, Purification of Sludge

\section{INTRODUCTION}

It is very important to reduce sedimentary sludge in the ocean. Plans to reduce the sludge are usually dreading or sand covering. Dredging is a simple way and aims to cut off the sludge. But after cutting off, treating the dredged sludge takes much more time and, of course, cost. Sand covering, in general, gives a big load to living organisms and the ecological system. Here, a more efficient way is needed to reduce the sludge while not imparting environmental load in the local sea area.

Now, we have micro-bubble technology. Micro-bubbles (that is $\mathrm{MB}$ ) can change conditions into an aerobic state. We had developed a method for decomposing the sludge by activating microorganisms in an aerobic state by micro-bubble. Our developed experimental apparatus is shown in Fig.1 in [1], [2]. We had very good results; for example, it could be reduced the treatment days to 5 days. We had also understood that hydrogen sulfide is reduced at first in an aerobic state by micro-bubble and then the nutrients will be reduced, shown in Fig. 2.

Here, we have also a technique for purification by using "coagulants". We had also very good results by using coagulants in [3].

In this paper, we propose the way which hydrogen sulfide is reduced at first by using coagulants and then the nutrients and activating Microorganisms in [1],[2].

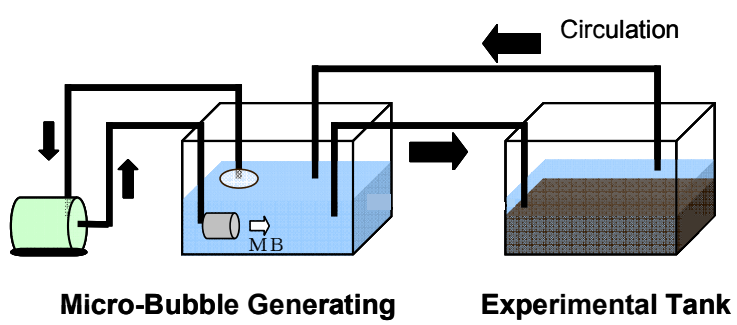

Fig.1 Experimental apparatus by micro-bubble and activating Microorganisms in [1],[2] will be reduced in an aerobic state by micro-bubble and activating microorganisms, since we are going to reduce the treatment days more. We used the detergents including enzyme as the microorganism activator, since we can obtain it easily and also put on the market, in [4]. Oral-presented non-refereed conference paper [5] expressed this proposed experimental system but the results had been unstable and not suitable.

Our research object in this paper is to check the stability and the purification performance, since we can show the proposed experimental system has been stable and good suitable by our obtaining very good results.

\section{NEW EXPERIMENTAL SYESTEM}

Our proposed method for purification experiment has two steps. First step is that a hydrogen sulfide is reduced at first by using coagulants. Second step is that the nutrients will be reduced in an aerobic state by micro-bubble and activating microorganisms.

\subsection{Experimental Apparatus and Procedure in Step 1}

Sludge and seawater were put in the tank (Long70 $\mathrm{xWidth} 47 \mathrm{xHeight} 28 \mathrm{~cm}$ ) and then were mixed by a water pump (300litter/hour) for 10 minutes after coagulants were put in, shown in Fig.3.

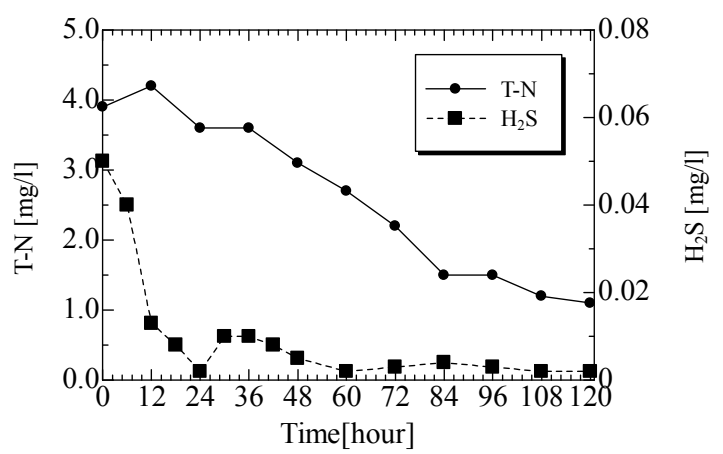

Fig. 2 General results of $\mathrm{H}_{2} \mathrm{~S}$ and $\mathrm{T}-\mathrm{N}$ by micro-bubble and activating Microorganisms by [1],[2] 
Here, seawater is 90 (litter) and ocean sludge is $3(\mathrm{~kg})$ which were picked up from Funabashi Port in Tokyo in Japan, as shown in Fig.4 and 5. Concentration of coagulants was 400 (ppm). After sludge was changed into flocculated situation, flocculated sludge will be used for reuse and the remaining seawater is used for next experiment in step 2 .

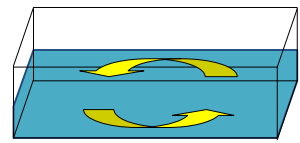

Mixing Tank

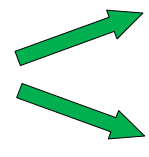

Flocculated Sludge

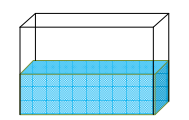

Remaining Seawater
Fig.3 Schematic Representation of Experimental Apparatus in Step 1
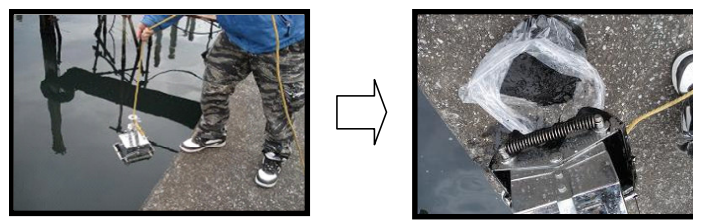

Fig.4 Gathering Instrument for Sludge

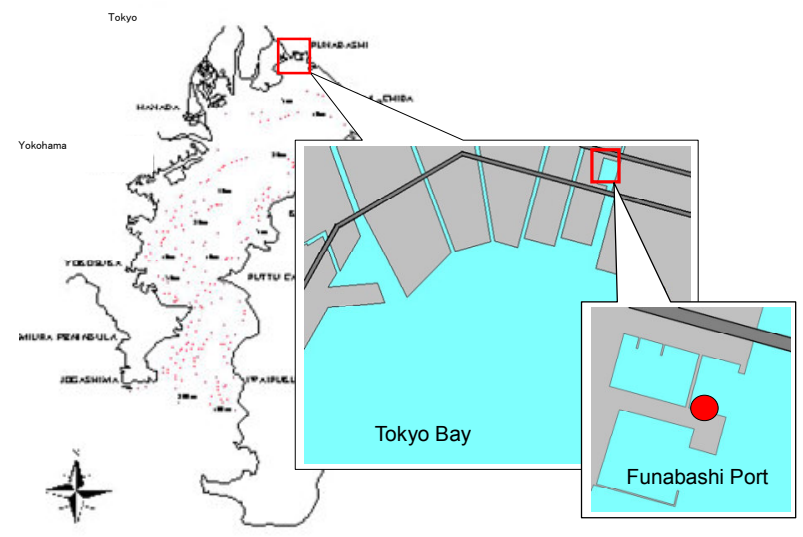

Fig.5 Catching Point of Sludge at Funabashi Port in Tokyo Bay

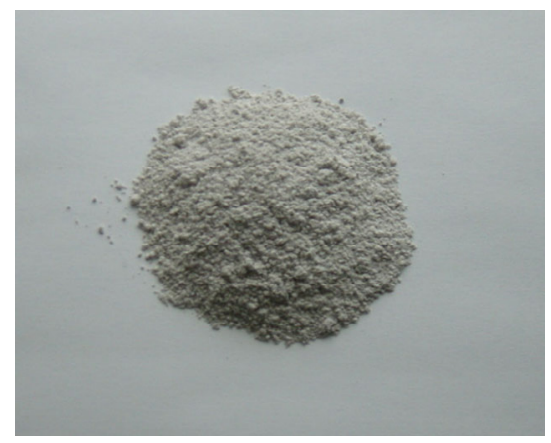

Fig. 6 Coagulants in this Research

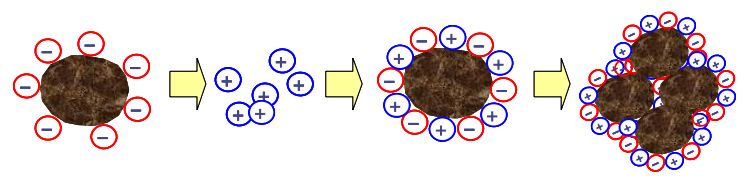

Fig. 7 Mechanism of Coagulants

\subsection{Coagulants in this Paper}

Our used coagulants are neutral and inorganic substance, shown in Fig.6. This is neutral and inorganic and the main ingredients of this are compound alumina and silicate. When we use this, we have to mix strongly with water after putting in. This has a characteristic of adsorption and fix-separation to cohere not only nasty substance of floating but also dissolving. This has also a characteristic of good desiccate and fixing heavy metal stable. Reaction mechanism of the coagulants is shown in Fig.7, in [6].

\subsection{Experimental Apparatus in Step 2}

The experimental devices in step 2 consist of two parts, shown in Fig. 8 and 9. This step is the same as the ordinary experiment system in [1],[2].

The water circulates through two tanks. In one tank (Width40xLength28xHight28cm), micro-bubbles are generated. The micro-bubbles have micro-size diameter and high solubility. This means the water with high concentration of dissolved oxygen circulates through these tanks. The other part is the experimental tank (W60xL29xH35cm). The remaining seawater in step 1of our experiment is put in this tank. Here, a micro-bubble generator is based on [7] and the flow rate is 1200 (litter/hour). The flow rate of water pumps connected each tanks are 300 (litter/hour).

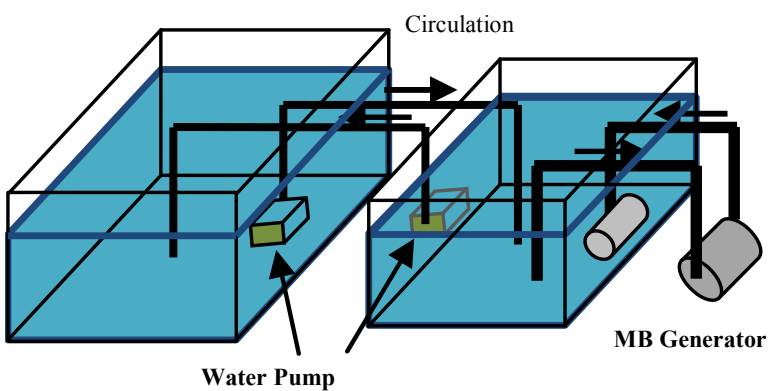

Experimental Tank

MB Generating Tank

Fig. 8 Schematic Representation of Experimental Apparatus in Step 2

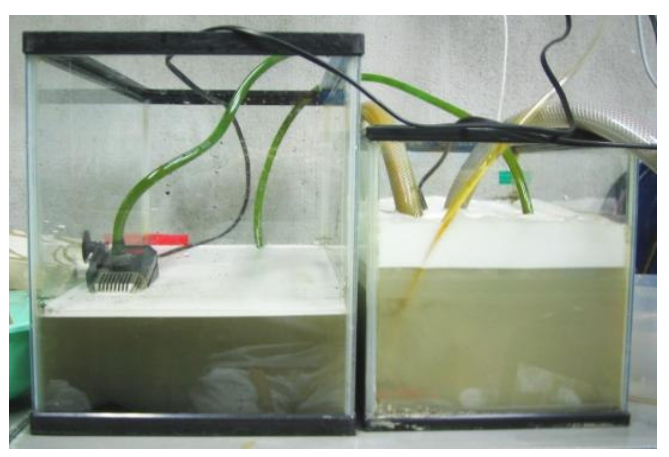

Fig. 9 Picture of Experimental Apparatus in Step 2

\subsection{Experimental Procedure in Step 2}

After creation of flocculated sludge by experiment as Step 1, the remaining seawater was put in the tank, and then the micro-bubble device and the water pumps were powered on. Here, room temperature was set 25 degrees Celsius by an 
air conditioner. After 6 hour, the microorganism activator was put in the experimental tank.

In this experiment, one kind of detergent including enzyme as the microorganism activator is used by the reasons denoted the best results in [4]. Including enzyme in the detergent are mainly lipase, protease and amylase. Amount of the detergent as experimental conditions are shown in Table. 1. The appropriate weight of this detergent is 10 (gram). For comparison, there is one more case by using the microorganism activator which had been getting effective results in purification for grease trap at gas station, written by [2], so this case is named "Case 4, 2008".

The amount of sludge and seawater is $1(\mathrm{~kg})$ and 30 (litter), per an experimental case.

Dissolved oxygen (DO), water temperature and $\mathrm{pH}$ are measured by using of multi-parameter water quality meter. Ammonium nitrogen $\left(\mathrm{NH}_{4}-\mathrm{N}\right)$, total nitrogen $(\mathrm{T}-\mathrm{N})$ and total phosphorus (T-P) are measured by using of digital-water-analyzer by digital "Packtest", by water filtered after sampling in experimental tank.

Table.1 Amount of Detergents as Experimental Conditions

\begin{tabular}{|c|c|}
\hline Case & $\begin{array}{c}\text { Amount(Times) } \\
\text { (Additional / Appropriate) }\end{array}$ \\
\hline$(1)$ & 5 \\
\hline 2 & 6 \\
\hline 3 & 7 \\
\hline (4) & Reference by Okamoto et al. in 2008 \\
\hline
\end{tabular}

\section{RESULTS AND CONSIDERATION}

\subsection{Effects on Experiment of Step 1}

Results of the experiment of step 1 by using coagulants are shown in Table. 2 . The results on water temperature and $\mathrm{pH}$ are a little change, compared with each other. We can see the situation changed into an aerobic state from the results on DO by mixing sludge with coagulant. We can also see the results of $\mathrm{H}_{2} \mathrm{~S}$ were decreased zero by the experiment of Step 1. On the other hand, the results on the nutrients; $\mathrm{NH}_{4}-\mathrm{N}$ and T-N also decrease to 70 and $53 \%$.

Table.2 Results on Experiment of Step 1

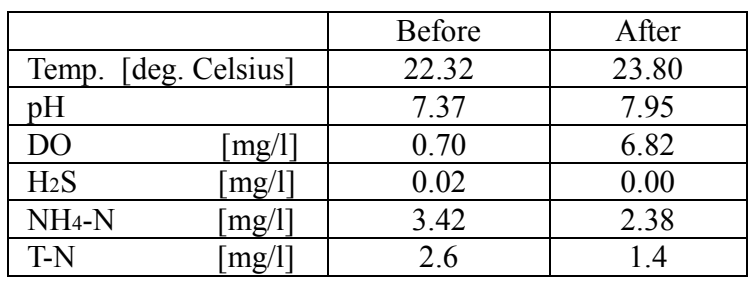

\subsection{Effects on Experiment of Step 2}

(1) Effects on the density of sulfate and the contents of sulfur. Checking the mechanism in this experimental system, the density of sulfate was analyzed in Case 2. The density of sulfate is shown in Fig. 9, adding the results by [2] in 2008 which is Case 4 . The results were obtained by the iron chromatography. It seems that sulfate increases due to the activity of sulfur bacteria in Case 4 . But the density of sulfate in Case 2 doesn't increase. It seems the reduction of
$\mathrm{H}_{2} \mathrm{~S}$ became by lower density of sulfate, and microorganisms also were reduced a little by experiment of step 1 .

The content of sulfur is shown in Fig.10, adding the results by [2] in 2008 which is Case 4 . The results were obtained by the elementary analysis. Especially in Case 4, the content of sulfur up to 6 hours did not change but after 6 hours it decreased rapidly since the activator of microorganisms was put in the experimental tank after 6 hours. But the content of sulfur in Case 2 is almost zero. It seems that microorganisms changed the sludge into the sulfur by the ordinary method, but the present method could not change the sludge into the sulfur.

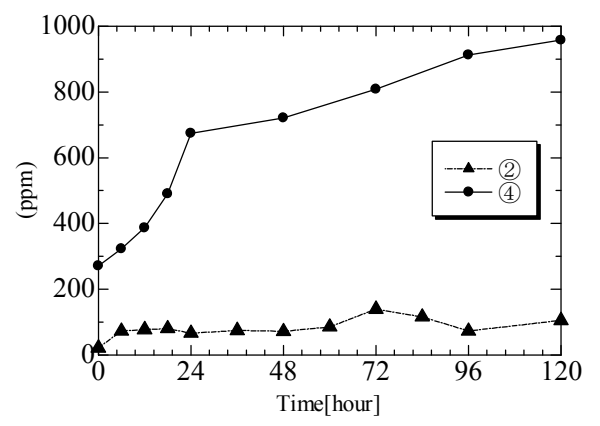

Fig. 9 Results of the Density of Sulfate in Step 2

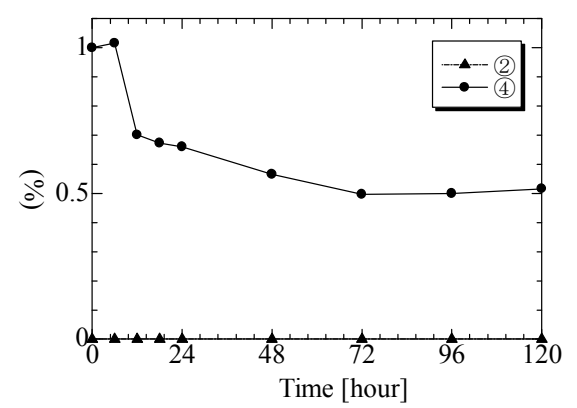

Fig.10 Results of the Content of Sulfur in Step 2

\section{(2)Effects on $\mathrm{H}_{2} \mathrm{~S}$.}

Measured results of $\mathrm{H}_{2} \mathrm{~S}$ in all cases are shown in Fig. 11 . The result in Case 4 is a usual tendency. On the other hand, the results in Case 1, 2 and 3 are almost zero. It seemed coagulants in the experiment of Step 1 reduced $\mathrm{H}_{2} \mathrm{~S}$. From the results, our method is very good.

(3)Water Temperature, pH and DO as Environmental Conditions for Experiment of Step 2.

Measured results of water temperature, $\mathrm{pH}$ and $\mathrm{DO}$ in all experimental cases are shown in Fig.12 to Fig.14, respectively. Water temperature up to 24 hours increased rapidly and then became constant about 25 to 30 degree Celsius. It seems this was caused by the heat from friction of the micro-bubble device. The tendency of $\mathrm{pH}$ has up and down in Case 1, 2 and 3, but became constant about 7.6 to 8.5. It seemed it is better to use for experiment. Dissolved oxygen (DO) in Case 4 up to 12 hours increased and then became constant. It seems oxygen dissolved and reached the saturation point. Case 1, 2 and 3 have a tendency of up and down but these have enough oxygen by experiment of Step 1. From these results, we can recognize anaerobic state 
changing into aerobic state. It seems that these results are very good conditions for growth of microorganisms.

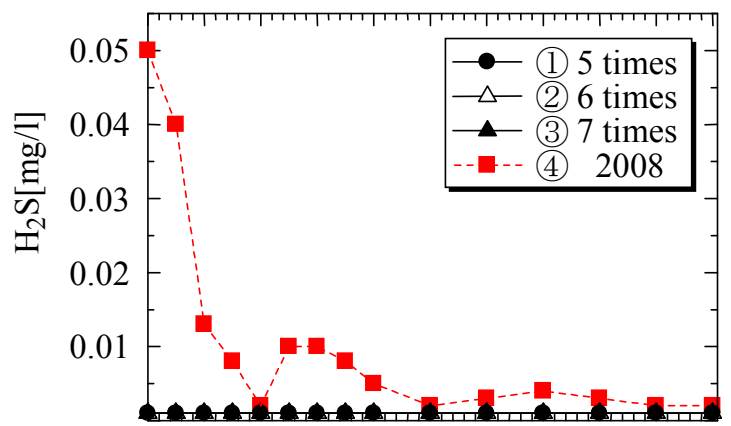

$\begin{array}{lllllllllll}0 & 12 & 24 & 36 & 48 & 60 & 72 & 84 & 96 & 108 & 120\end{array}$ Time[hour]

Fig. 11 Changes in $\mathrm{H}_{2} \mathrm{~S}$ by Experiment of Step 2

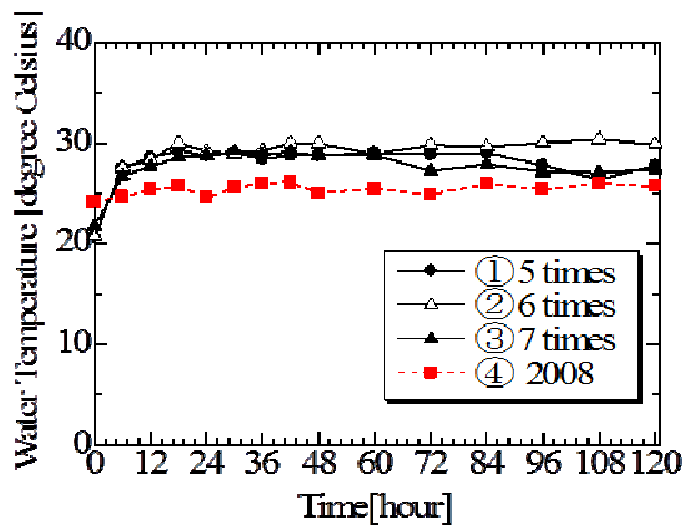

Fig.12 Changes in Water Temperature as Environmental Conditions by Experiment of Step 2

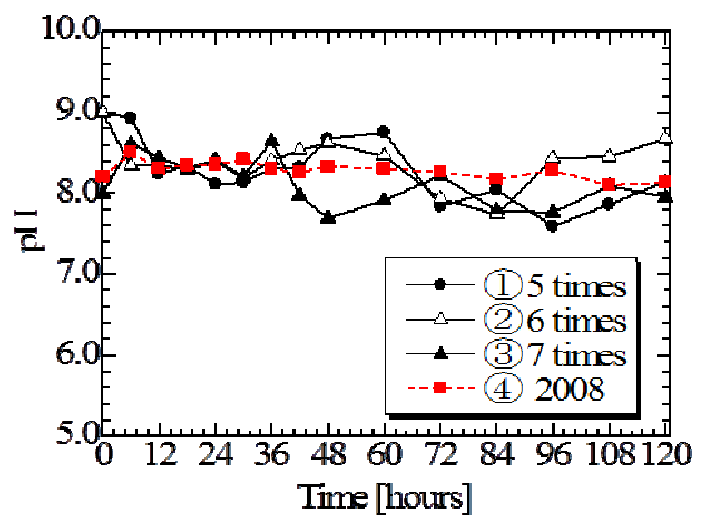

Fig.13 Changes in $\mathrm{pH}$ as Environmental Conditions by Experiment of Step 2

(4)Effects on $\mathrm{NH}_{4}-\mathrm{N}, \mathrm{T}-\mathrm{N}$ and T-P.

Measured results of $\mathrm{NH}_{4}-\mathrm{N}$ in Cases 1, 2 and 3 are shown in Fig. 15. The results of $\mathrm{NH}_{4}-\mathrm{N}$ in Case 1 and 2 decrease and become zero until 24 hours. But the result after 84 hours in Case 1 and 3 increase a little. It seemed the Case 2 has very good result, compared with Case 1 but Case 1 and 3 become no effect after 84 hours. Measured results of T-N and T-P in all cases are shown in Fig. 16 and Fig.17. The results of T-N have a tendency of decrease until 84 hours. Case 2 has very good results that $\mathrm{T}-\mathrm{N}$ is purified until 24 hours. On the other hand, the results in Case 1, 2 and 3 after 96 hours increase unexpectedly. It seemed Case 2 has very good performance for T-N, but the results are not effective after 96 hours. The results of T-P in Case 1 and 2 have good performance, compared with Case 4 by results in 2008. The results of T-P in Case 2 become no effect after 96 hours.

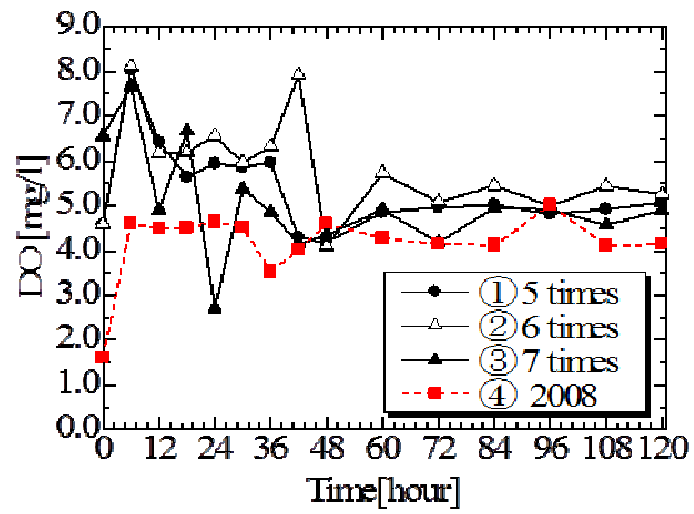

Fig.14 Changes in DO as Environmental Conditions by Experiment of Step 2

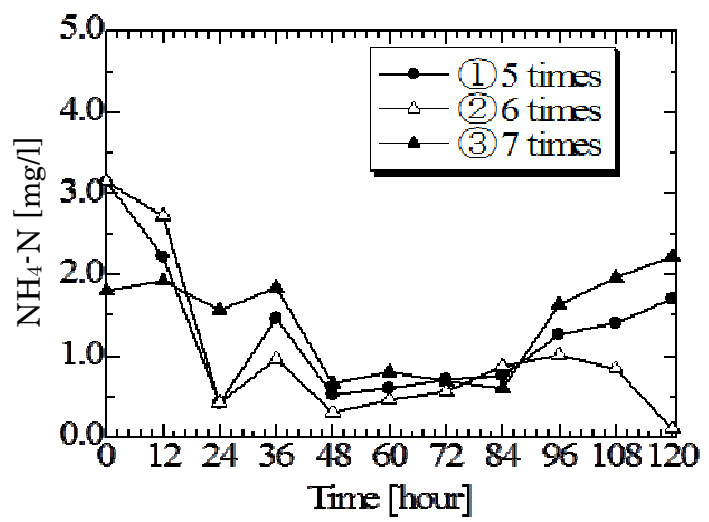

Fig. 15 Changes in $\mathrm{NH}_{4}-\mathrm{N}$ for Experiment of Step 2

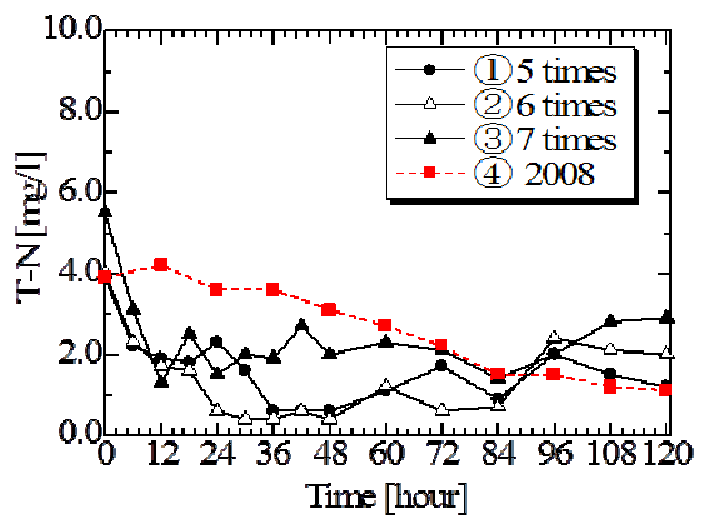

Fig. 16 Changes in T-N for Experiment of Step 2

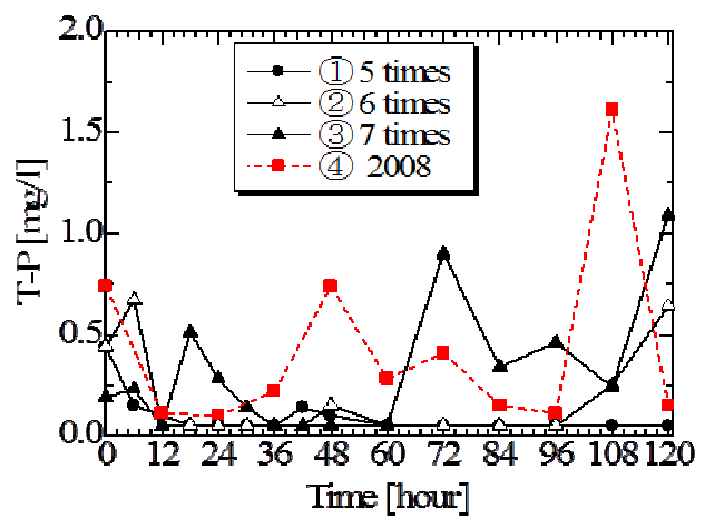

Fig. 17 Changes in T-P for Experiment of Step 2 


\section{RSULTS OF RE-EXPERIMENT AND CONSIDERATION}

It seems our proposed method is very good until 84 hours from the results of experiment of Step 2. For getting the best purification, we had carried out re-experiments to put the activator twice in experiment of step 2 , because the results are not effective after 96 hours.

\subsection{Re-Experiments}

Experimental conditions for the method of adding the activator twice are shown in Table. 3. Second adding amount of Case 5, 6, 7 is 2, 4, 6 times of activator at time $=60$ hours, respectively. For comparing the effects, the results of Case 2 in experiment of step 2 are used. The other conditions are almost same of experimental of step 2 . Measured results on environmental condition of this re-experiment were also almost same of experiment of step 2.

\subsection{Effects on $\mathrm{NH}_{4}-\mathrm{N}$ and $\mathrm{T}-\mathrm{N}$}

Measured results of $\mathrm{NH}_{4}-\mathrm{N}$ in Cases 5, 6 and 7 are shown in Fig. 18, with Case 2 in experiment of step 2. The results of T-N and T-P are also shown in Fig.19, 20, respectively.

The re-experimental system has very good performance from these results. $\mathrm{NH}_{4}-\mathrm{N}$ of Case 5 can be purified. T-N of Case 5 and 6 can be also purified. T-P of Case 5 can be also purified.

It seems that we could get very good performance for purification by adding the activator of microorganisms and reduce the time for purification, since purification performance was shortage from the results in experiment of step 2 .

Table.3 Method of Adding Activator as Re-Experimental Conditions

\begin{tabular}{|c|c|c|}
\hline \multirow{2}{*}{ Case } & \multicolumn{2}{|c|}{$\begin{array}{c}\text { Method of Adding Activator } \\
\text { (Amount(Times)=Additional/Appropriate) }\end{array}$} \\
\hline & $\begin{array}{l}\text { First adding } \\
\text { at time }=0\end{array}$ & $\begin{array}{l}\text { Second adding } \\
\text { at time }=60 \text { hour }\end{array}$ \\
\hline (5) & \multirow{4}{*}{6 times } & 2 times \\
\hline (6) & & 4 times \\
\hline (7) & & 6 times \\
\hline (2) & & 0 \\
\hline
\end{tabular}

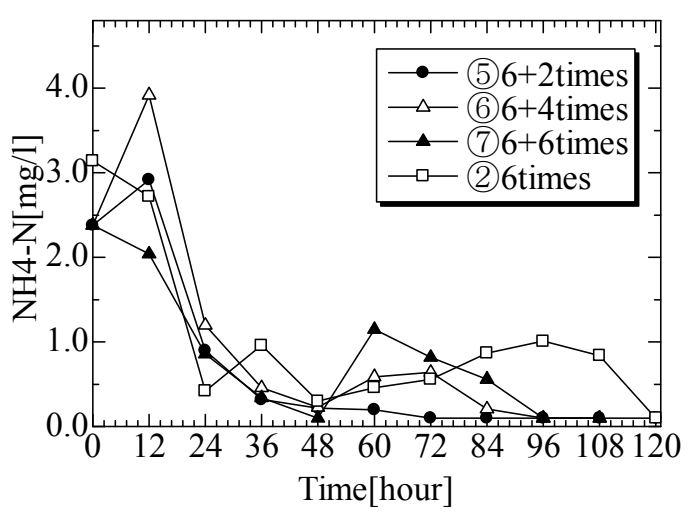

Fig.18 Results on $\mathrm{NH}_{4}-\mathrm{N}$ by Re-Experiment

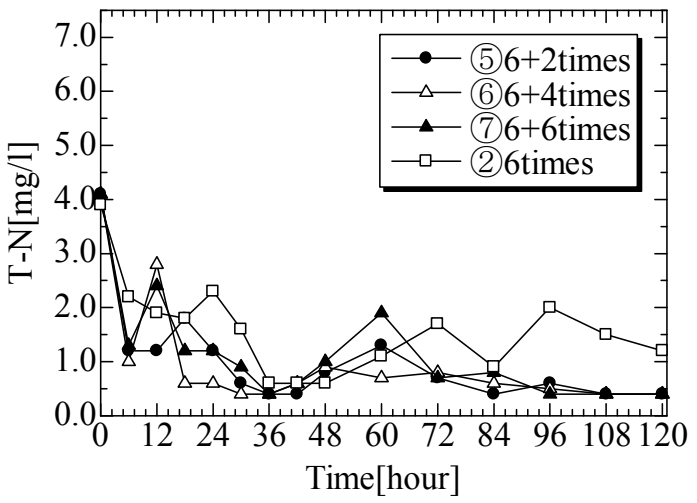

Fig.19 Results on T-N by Re-Experiment

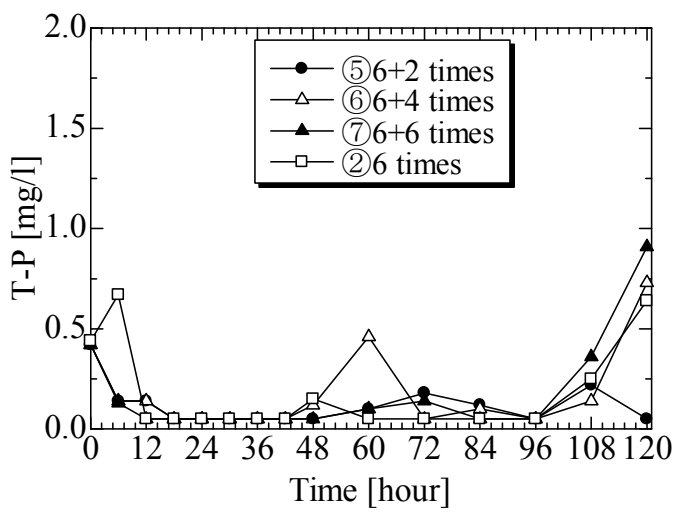

Fig.20 Results on T-P by Re-Experiment

\section{CONCLUSIONS}

We proposed the system which hydrogen sulfide is reduced at first by using coagulants and then the nutrients is reduced in an aerobic state by micro-bubble and activating microorganisms. Here, we used the detergents including enzyme as the microorganism activator.

We also carried out purification experiments and then checked the stability of experimental apparatus the purification performance for sludge by our proposed experimental system. From the results by the experiment of Step 1 and 2,

1) It seemed coagulants in the experiment of Step 1 reduced $\mathrm{H}_{2} \mathrm{~S}$.

2) It seemed microorganisms also are reduced a little by coagulants in the experiment of step 1.

3) The performance of purification in Case 2 is very good for the results on $\mathrm{T}-\mathrm{N}$ and also $\mathrm{NH}_{4}-\mathrm{N}$, until 84 hours.

4) The results of T-P in Case 1 and 2 have good performance, compared with the results in 2008.

Here, we carried out re-experiment which was put twice of activator at 0 and 60 hours, since the purification performance was shortage from the results in experiment of step 2 . From the results by re-experiment, we could get very good performance for purification and reduced the time for purification.

Finally, it is seemed our proposed experimental system has stability and very good performance, so that we can understand the system is effective. 


\section{ACKNOWLEDGMENT}

The authors would like to express sincere thanks to Dr. T. Toyama, Nihon University, in Japan

\section{REFERENCES}

[1] Okamoto K, Hotta K, Toyama T, and Kohno H, "Experiments on purification of ocean sludge by activating microorganisms," Proc. of ISOPE-2011-TPC-574, 2011.

[2] Okamoto K, and Hotta K, "Purification experiments on sedimentary sludge by microorganism activator," Proc. of Pacific Congress on Marine Science and Technology (PACON2008).

[3] Okamoto K, and Hotta K, "Experiment on purification for water quality by using of cohesion powder," Proc. of ISOPE-2006-JSC-306, 2006.

[4] Okamoto K, Hotta K, Toyama T, and Kohno H, "Purification experiments of ocean sludge by activating microorganisms -by using detergent including enzyme as the activator-," Proc. of ISOPE-2012-TPC-379, 2012

[5] Okamoto K, and Hotta K, et al., "Purification Experiments by Using Coagulants and Activating Microorganisms with Micro-bubble Device", 55th Annual Conference, Faculty of Science and Technology, Nihon University, 2011

[6] Matsui R, Okamoto K and Hotta K, "Water Purification Experiments by Micro Bubble," Book of Recent Advances in Marine Science and Technology, 2006, pp.119-126.
[7] Imai T, Shioshige K, Ukita M, Sekine M, Higuchi T, Fukagawa K and Fujisato T, "Development of Device for Dissolving High Concentration Gas for Purification at bottom layer around enclosed water area like Dam Lake," Proc. 39th Forum on Environmental Engineering of Civil Engineering Society, 2002, 10-12.

[8] Matsuo K, Maeda, K, Ohnari, H, Tsunami, Y, and Ohnari, H, "Water Purification of a Dam Lake Using Micro Bubble Technology," Progress in Multiphase Flow Research I, 2006, pp.279-286

[9] Mizoguchi M, "Observation of Water Purification Process in a Moat by Microbiological Treatment Technique," Proc. of Biological Resource in Mie University, No.16, 1996, pp.25-37.

[10] Hibino T and Matsumoto H, "Distribution of Fluid Mud Layer in Hiroshima Bay and its Seasonal Variation", Proc. Civil Engineering, Vol. 62, No 4, 2006, pp.348-359.

\section{Int. J. of GEOMATE, June, 2013, Vol. 4, No. 2 (Sl. No. 8), pp. 574-579.}

MS No. 229 received June 12, 2012, and reviewed under GEOMATE publication policies.

Copyright (C) 2013, International Journal of GEOMATE. All rights reserved, including the making of copies unless permission is obtained from the copyright proprietors. Pertinent discussion including authors' closure, if any, will be published in the June 2014 if the discussion is received by Dec., 2013

Corresponding Author Kyoichi Okamoto 